\title{
Assessment of Modern Contraceptive Utilization and Associated Factors Among Women Living With HIV/AIDS In Debre Tabor Referral Hospital In Debre Tabor Town, South Gondar Zone, North Central Ethiopia
}

Endeshaw Chekol Abebe

Debre Tabor University

Teklie Mengie ( $\nabla$ tekliepharm@gmail.com )

Debre Tabor University https://orcid.org/0000-0002-4578-5388

Tadesse Asmamaw Dejenie

University of Gondar

Zelalem Tilahun Muchie

Debre Tabor University

Research

Keywords: HIV/AIDS, Family planning, Contraceptive, Factors, Utilization

Posted Date: January 7th, 2021

DOl: https://doi.org/10.21203/rs.3.rs-140041/v1

License: (9) This work is licensed under a Creative Commons Attribution 4.0 International License.

Read Full License 


\section{Abstract}

Introduction: Preventing unintended pregnancy among HIV-positive women constitutes a critical global public health priority for addressing the desperate state of maternal and child health in HIV hyper endemic settings, yet few data exist on contraceptive use among women entering ART follow up in Debre Tabor Referral Hospital.

Objective: The main objective of this study was to assess contraceptive utilization and associated factors among women aged 15-49 years living with HIV/AIDS in Debre Tabor Referral Hospital.

Methods: Institution based cross-sectional study was conducted from January 02 to February 03, 2020 on women aged 15-49 years living with HIV/AIDS in Debre Tabor Referral Hospital. A total of 415 reproductive women living with HIV/AIDS were selected for the study using simple random sampling technique. Data was collected using a Structured questionnaires through face to face interview by two trained nurses assigned at ART clinic of DTH during data collection period. The data was presented using descriptive statistics of frequency and percentage and the association between dependent and selected independent variables was determined by inferential statistics of chi-square test.

Result: The study analysis shows that there is significant association ( $p$-value $<0.05)$ between educational status ( $p$-value $=0.000)$, knowledge about modern contraceptive ( $p$-value $=0.000)$, spouse approval $(p$ value $=0.000)$ and receive counseling about modern contraceptive $(p$-value $=0.000)$ with their modern contraceptive use.

Conclusion: This study in generally showed lower utilization of modern contraceptive in the study area.

\section{Plain English Summary}

Adding family planning services to care and treatment might facilitate the uptake of contraception by HIV-positive individuals, helping to maintain their health, plan safer pregnancies, and reduce the rate of mother-to-child transmission of HIV. This research project assisted the utilization of contraceptives among women who are on ART follow up in the study area. In this study all (415) of the study participant had ever heard about modern family planning. Only $45.3 \%$ study participants commonly use health care professionals as means of information source related to contraceptive. Utilization pattern of women living with HIV/AIDS also increased.

In conclusion; this study showed that a significant number of women living with HIV/AIDS were not currently using modern contraceptive. Factors such as not being married or in relationship, want to get pregnant and because of infertile negatively affect the use of contraceptive in patients living with HIV/AIDS.

\section{Introduction}


Family planning saves lives of women and children and improves the quality of life for all. It is one of the best investments that can be made to help ensure the health and well-being of women, children, and communities (1). Adding family planning services to care and treatment might facilitate the uptake of contraception by HIV-positive individuals, helping to maintain their health, plan safer pregnancies, and reduce the rate of mother-to-child transmission of HIV. Contraceptive use among HIV-positive women might also contribute to fewer child deaths, avert orphan hood, and reduce maternal mortality. Including HIV services, particularly counseling and testing, in FP services would allow earlier diagnosis and referral to care and treatment. Prevention of unintended pregnancies among HIV-positive women is one of the four elements considered essential in a comprehensive strategy to prevent HIV infections in infants. Indeed, there is broad international consensus that the goal of preventing mother-to-child transmission of HIV cannot be met without increasing access to FP services (2). Family planning services must be comprehensive and address HIV prevention including, where appropriate, the benefits of abstinence, the risk associated with unprotected sex with multiple partners as well as the promotion and provision of dual protection. Helping women living with HIV/AIDS to prevent unintended pregnancies is an important, though often neglected, approach to preventing HIV transmission to infant (3). The emergence of HIV has increased the already heavy burden of disease and death among women and children in low- and middleincome countries. This epidemic is now affecting the modest gains made in the previous decades in maternal and child survival and has had devastating effects on families, households and communities (4).

Ethiopia is among the countries most affected by the HIV pandemic with an estimated adult prevalence of 1.5. In 2011, Women have a higher HIV prevalence (1.9\%) than men (1\%) (5). According to the 2007 single point HIV prevalence estimate of Ethiopia for the year 2010, 90,311 HIV positive pregnant women and there were 14,276 annual HIV positive births (6).

Developing sexual and reproductive health services to meet the reproductive health care needs of people living with the HIV are growing concerns of HIV prevention. ART use is associated with significantly higher pregnancy rates among HIV positive women (7). Three times as many infants are spared HIV infection by current contraceptive use compared to providing antiretroviral treatment to mothers during pregnancy, birth and breastfeeding (8). However, little attention has been given to family planning for HIV positive women as critical components of HIV prevention, care and treatment services. Despite the potential contribution of FP to the prevention of HIV infection and transmission, contraceptive use in subSaharan Africa, including condom use, remains low (9). The most recent Demographic Health Survey (DHS)data indicate that the percentage of married women aged 15-49 using modern method of contraception $11.1 \%$ in Mozambique, 25\% Zambia, 26\% Uganda and 27\% in Ethiopia (5,9-13). This emphasizes the public health significance of providing effective FP services to PLWH. Besides, there is no research done specifically assessing the utilization of contraceptives among women living with HIV/AIDS who are on ART follow up in the study area. Hence the study was aimed to assess contraceptive utilization and associated factors among women living with HIV/AIDS and thereby assists to increase the utilization of contraceptives among women living with HIV/AIDS. It is hoped that this study help to increase the utilization of contraceptives among women living with HIV/AIDS. The finding from this study 
may also provide relevant information for policy maker and NGOs for future planning and to carry out appropriate intervention to promote and maintain the contraceptive use among women living with HIV/AIDS and thereby contribute for increment of contraceptive prevalence rate and reaching sustainable development goals by decreasing maternal and child mortality. Moreover, the study will serve as baseline data for further research of the same topic. Health Professional will also benefit from the study as guidelines and recommendations pertaining to the prevalence of contraceptive use among women living with HIV/AIDS, will update their knowledge and skills regarding this phenomenon.

\section{Objectives}

The objective of this study is to assess contraceptive utilization and associated factors among women living with HIV/AIDS in Debre Tabor Referral Hospital in Debre Tabor town, South Gondar Zone, North central Ethiopia, January 2020.

\section{Methods}

\section{Study area, period and design}

Institution based cross-sectional study was conducted from January 02 to February 03, 2020 on women aged 15-49 years living with HIV/AIDS in Debre Tabor Referral Hospital (DTRH) in Debre Tabor Town, Northwest Ethiopia.

\section{Population}

All HIV positive women aged 15-49 years who visit Debre Tabor Referral Hospital for ART follow up were considered as Source population while sampled HIV positive women aged 15-49 years on ART follow up who fulfill the inclusion criteria and available during the study period were taken as study population.

\section{Eligibility criteria}

All women in age group 15-49 years on ART follow up and had at least one visit in ART clinic of Debre Tabor Referral Hospital were included in the study. Those seriously ill to be interviewed and those women who were newly enrolled to start ART i.e. not more than one month since ART regime started were excluded from the study.

\section{Study Variables}

Utilization of Contraceptive method considered as dependent variable whereas socio demographic variables (age, educational status, occupation, marital status, religion, income); client related factors 
(knowledge about contraception, attitude toward contraceptive use, number. of children); method related factors (side effects related to contraceptive use) and service related factors (Counseling of contraceptive use, availability of contraceptive service) were independent variables.

\section{Operational definitions}

Utilization of modern Contraceptive: practice of using at least one contraceptive such as pills, injectable (Depo-Provera), condoms, implants, Intra uterine contraceptive devices, and bilateral tubal legation. Women on ART follow up: Women who visit to the selected ART treatment unit for receiving Pre ART or ART service. Knowledge about contraceptives: a woman aware of at least four or more methods of contraception. Attitude: Attitude is the belief that the women living with HIV/AIDS have towards modern contraceptive use; Dual method use: Using two methods of contraception i.e. a barrier method for protection against sexually transmitted infections (STIs) and another method for protection against unintended pregnancy.

\section{Sample size determination and Sampling procedures}

The sample size for the study was determined using a single population proportion formula by assuming prevalence of contraceptive utilization () of $57.7 \%$ from another similar study conducted in Southern Ethiopia among HIV positive women (14).

$$
\mathrm{n}=(\mathrm{Z \alpha} / 2)^{2} \times(\mathrm{p}) \times(1-\mathrm{p})
$$

$(\mathrm{d})^{2}$

Where; $\mathrm{n}=$ the desired sample size; $\mathrm{Za} \backslash 2=$ Standard normal value at $95 \%$ confidence interval $=1.96 ; \mathrm{p}=$ Expected proportion of population using contraceptives $=57.7 \%=0.57 ; q=1-p=0.43 d=$ absolute precision $=0.05$. After adding $10 \%$ non-response rate, the final sample size $(n)$ calculated was 415 clients. A total of 415 reproductive women living with HIV/AIDS were selected for the study using simple random sampling technique to select eligible participants from ART Clinic using ART registration book in DTRH.

\section{Data collection and statistical analysis}

Data was collected using a structured and pre tested questionnaires through face to face interview by two trained nurses assigned at ART clinic of DTRH during data collection period. After the data was collected, it was checked for completeness and internal consistency then it was sorted, grouped and stored using 
computer. Processed data was analyzed using descriptive statistics of frequency and percentage. The association between dependent and independent variables was determined by inferential statistics of chi square test using SPSS version 25.0 software. And p-values of $<0.05$ was considered as statistically significant.

\section{Data quality control}

The data was collected using structured questionnaire prepared in English and translated in to Amharic and then retranslated back in to English to check its consistency. Prior to the actual data collection period testing of the questionnaire was conducted on 21 women living with HIV/AIDS who were on ART follow up in Hidar 11 Health center in Debre Tabor town and necessary modification was made before being applied on the study participants.

Before data collection training was given for study participants to enable them to have understanding on the objectives of the study and each of the questions in the questionnaire. The data collection was supervised by the principal investigator. Every day, questionnaires was reviewed and checked for completeness of data collection by principal investigator and inconsistencies and errors on skip pattern were corrected accordingly.

\section{Ethical consideration}

Ethical clearance and permission was obtained from Debre Tabor University Research and Ethical Review Committee and also a written approval from Debre Tabor Referral Hospital Administrative office was given. The purpose and objective of the study were explained and written consent was obtained from each selected study participant. Participants were also informed that participation is on voluntary basis and they can withdraw from the study at any time. Confidentiality of information provided by study subjects has also been protected by making the data collection procedure anonymous.

\section{Results}

\section{Socio-demographic Characteristics of respondents}

A total of 415 participants were included in the study making the response rate $100 \%$. Of all respondents, $362(87.2 \%)$ were from urban. The age distribution of the respondents showed that, $152(36.6 \%)$ of the respondents were in the age group of 25-34 years. Three hundred eighty one (91.8\%) of women were Orthodox in religion; while Muslim constituted 24(5.8\%). Majority 404 (97.3\%) of the study participants were Amhara in ethnicity. Education level of respondents showed that $140(33.7 \%)$ had primary education. Regarding the marital status of the respondents, the majority $274(66.0 \%)$ of women were married whereas 69(16.6\%), 53(12.5), and 19(4.6) were widowed, divorced and single respectively. One hundred seventy seven (42.7\%) of the study participants were merchants while $144(34.7 \%), 71(7.5 \%)$ and 
24(5.8\%) were housewives, government employee and private employee respectively. Majority 319(76.9\%) of the study participants had monthly income of less than 3000 birr (Table 1).

\section{Knowledge about modern contraceptives}

All $(100 \%)$ of the study participant had ever heard about modern family planning. The most commonly mentioned sources of information were health professionals 188(45.3\%), Television 147(35.4\%), and Radio 129(31.0\%), respectively (Figure: 1). All participants were heard injectables and pills. The other contraceptive methods heard were implant, condom and IUCD which accounts $91.3 \%, 89.9 \%$ and $72.1 \%$ respectively (Figure:2).

\section{Utilization of modern contraceptive methods}

Three hundred eighty six (93\%) of participants ever used modern contraceptive. Around $328(85.0 \%)$ of participants ever used contraception after being HIV positive. One hundred thirty seven $(41.8 \%)$ of the women who participated in the study were currently using at least one method of modern contraceptive. Among the current contraceptive users (137), the most frequently used method of contraception was injectables (48.9\%) followed by pills and condom only which accounts $24.1 \%$ and $11.7 \%$ respectively. The other least frequently used methods by women were dual contraceptive (8\%), Implant (5.8\%) and IUCD $(1.5 \%)$ as a method of contraception. Out of the dual or condom only users $12(44.4 \%)$ reported consistent use of condom.

Majority of the respondent's reasons for condom use were to prevent unwanted pregnancy $19(70.4 \%)$. The other reasons were health worker advice $7(25.9 \%)$, fear of other STI $4(14.8 \%)$ and partner being HIV negative $3(11.1 \%)$. Women in the study who had heard of emergency contraception were found to be 275 $(66.3 \%)$. Forty two $(15.3 \%)$ of the women who have heard emergency contraception had ever used it. Among non users (233), only one in five women (19.9\%) had a desire to use emergency contraceptives in the future. One hundred ninety one $(58.2 \%)$ of women were not currently utilizing any modern contraceptive methods. Two third $94(66.6 \%)$ of women were not using modern contraceptives since they were not married or in a relationship. The other reasons were the need to get pregnant $87(45.5 \%)$, infertility $23(12 \%)$, partner disapproval $16(8.4 \%)$ and other reasons $7(3.7 \%)$. Out of non users, $58(34.6 \%)$ of respondent had desire to use modern FP in the future (Table: 2).

\section{Client/patient related characteristics of women living with HIV/AIDS}

Four hundred four (97.3\%) of respondents explained that their sero status did not affect their use of modern contraceptives. Half of the respondents $211(50.8 \%)$ had peer support to use modern contraceptives. Three hundred ninety eight $(95.9 \%)$ of women participated in the study reported that their religion did not affect their use of modern contraceptives. Out of 211 women in the study who were discussed about modern contraceptive methods with their partners, 200(94.8\%) were supported by their partner to use contraceptives (Table: 3 ).

\section{Service delivery related factors}


Out of the total respondents, $377(90.8 \%)$ received counseling about modern FP in the ART unit. Two hundred eighty three $(68.2 \%)$ of women reported that availability of ART \& PMTCT service did not affect their pregnancy desires. Out of ever users (386) of modern contraceptive methods, 369(95.6\%) had access to modern FP methods whenever they needed, 377 (97.7\%) of women explained that the hospital met their need for modern FP and 267 (69.2\%) of them explained that side effects of modern FP methods could not influence their choice of modern FP method (Table: 4).

\section{Factors associated with utilization of modern contraceptives}

The table (Table 5) illustrates the association between modern contraceptive use and selected variables in the study area. It shows that there is significant association ( $p$-value $<0.05)$ between the modern contraceptive use among women living with HIV/AIDS to their educational status $\left(X^{2}=33.9, p-\right.$ value $=0.000)$, knowledge of modern contraceptive $\left(X^{2}=236\right.$, $p$-value $\left.=0.000\right)$, spouse approval of contraceptive use $\left(X^{2}=58.3, p\right.$-value $\left.=0.000\right)$ and receive counseling about modern contraceptives $\left(X^{2}=184\right.$, p-value $=0.000$ ) (Table: 5).

The study tried to assess utilization of modern contraceptive utilization among women living with HIV/AIDS in Debre Tabor Referral Hospital. Modern contraceptive use was assessed; the study indicated that $93 \%$ of respondents ever used at least one modern contraceptive method. However, the utilization of modern contraceptive after they knew their HIV status and during the course of this study has dropped to $85 \%$ and $41.8 \%$ respectively. This finding is line with study done in Gimbi town, west Ethiopia ( $85.1 \%)$ ever modern contraceptives and (56.7\%) currently using contraceptives (15).

In this study $130(41.8 \%)$ of respondents were currently using modern contraceptive methods. The most frequent family planning methods used among HIV positive women were injectable and pills. This is comparable with the study done in Tigray, Ethiopia (46.3\%) (16). This is lower than another studies done in, Gimbie town, West Ethiopia (56.7\%), East Gojjam Zone, Ethiopia (53.6\%) and Addis Ababa, Ethiopia $(53.5 \%)(15,17,18)$.This variation could be because of difference in socio demographic characteristics including educational background, more than half of respondents in this study were achieved only primary school or below this and this possibly have effect on their awareness and utilization of contraceptives.

On the other hand, a study finding indicated that HIV-positive women currently using modern contraceptive in Soweto South Africa, (84\%) and Mbarara, Uganda $(85 \%)(19,20)$. These findings were higher than our study finding which may be due to socio-demographic difference, different health care system and treatment conditions under which the populations go through. Out of the dual or condom only users $44.4 \%$ of respondents were utilizing condom consistently, which is relatively lower than studies done in Lusaka, Zambia (73.5\%), Tigray, Northern Ethiopia (70\%) and Soweto, South Africa (64\%) $(16,19,21)$. The possible explanation for this discrepancy might be due to low prevalence of discordant rate and low educational status in this study. Modern FP methods other than condom use were very low, the result showed dual contraceptives (8\%), implant (5.8\%) and IUCD (1.5\%), this is comparable with 
study from Tigray Ethiopia. The majority of the respondent reasons for condom use were to prevent unwanted pregnancy $19(70.4 \%)$ and health workers advice $7(25.9 \%)$, this is in line with study done in Lusaka Zambia (16).

Factor associated with utilization of modern contraceptive identified in this study was respondent's educational status. Women's' educational status is statistically associated with their use modern FP methods. This finding was also in line with study done in Tigray Ethiopia, Lusaka Zambia, East Gojam zone, Ethiopia $(16,18,21)$. On contrary study done in Addis Ababa, Ethiopia and Gimbi town, west Ethiopia result indicated that educational status had no effect on modern contraceptive use $(15,17)$. Possible explanation for this finding is those women attending primary and above level of education had knowledge of modern contraceptive methods, (89.9\%) and knowledge of risk of mother to child transmission of HIV/AIDS (96.6\%) in this study. Women who had knowledge about contraceptives were more likely to use modern contraceptive, and also women who had spouse approval and who received counseling about modern contraceptives were more likely to use modern contraceptive. This finding was consistent with study from Gondar town, Northwest Ethiopia, and Makerere University Uganda irrespective of their HIV status $(22,23)$.

In the chi square test of live children and peer support were found to be not significantly associated with the use of modern contraceptive. This finding is in line with study result done in Southwestern, Uganda, Gimbie town, West Ethiopia and Asella Hospital, Ethiopia $(15,24,25)$. In this study even though $100 \%$ of study participant have ever heard about modern contraceptives, currently only $41.8 \%$ of them were using any of modern contraceptive, and the emergency contraception ever use was still low (46\%).

\section{Conclusion}

This study showed that a significant number of women living with HIV/AIDS were not currently using modern contraceptive. Among those using modern contraceptive, almost half of participants were using injectable type of modern contraceptive. Only one in five of them were currently using condom or dual method.

The three major reasons for not using modern contraceptive methods were not being married or in relationship, want to get pregnant and because of infertile. Important factor which had strong association with modern FP use were education level, knowledge of contraceptive, spouse approval and receive counseling about modern contraceptives.

\section{Abbreviations}




\begin{tabular}{|ll|}
\hline AIDS & Acquired Immuno Deficiency Syndrome \\
\hline ART & Anti-Retroviral Therapy \\
\hline CL & Confidence Level \\
\hline DHS & Demographic and Health Survey \\
\hline DTU & Debre Tabor University \\
\hline FHI & Family Health International \\
\hline FP & Family Planning \\
\hline HIV & Human Immuno Deficiency Virus \\
\hline IUCD & Intra Uterine Contraceptive Device \\
\hline MDGs & Millennium Development Goals \\
\hline NGO & Non-Governmental Organization \\
\hline PLWH & People Living With HIV AIDS \\
\hline PMTCT & Prevention of Mother to Child Transmission \\
\hline RVI & Retro Viral Infection \\
\hline SNNP & Southern Nations and Nationality of Ethiopia \\
\hline SPSS & Statistical Package for Social Sciences \\
\hline STI & Sexually Transmitted Infection \\
\hline WHO & World Health Organization \\
\hline
\end{tabular}

\section{References}

1. Tafese F, Woldie M, Megerssa B. Quality of family planning services in primary health centers of Jimma Zone, Southwest Ethiopia. Ethiop J Health Sci. 2013;

2. Adamchak S, Janowitz B, Liku J, Munyambanza E. Study of Family Planning and HIV Integrated Services in Five Countries Final Report. Research Triangle Park, NC: FHI. 2010.

3. UNAIDS. Countdown to zero: Global plan towards the elimination of new HIV infections among children by 2015 and keeping their mothers alive, 2011-2015. UNAIDS. 2011.

4. Sexual and reproductive health of women living with HIV / AIDS Sexual and reproductive health of women living with HIV / AIDS. WHO.

5. Chakrapani V, Kershaw T, Shunmugam M, Newman PA, Cornman DH, Dubrow R. Prevalence of and barriers to dual-contraceptive methods use among married men and women living with HIV in India. Infect Dis Obstet Gynecol. 2011; 
6. Odutola A, Baisley K, Hayes RJ, Rusizoka M, Tanton C, Weiss HA, et al. Pregnancy and contraceptive use among women participating in an HIV prevention trial in Tanzania. Sex Transm Infect. 2012;88(6):436-43.

7. World Health Organization. Guidance on Global Scale-Up of the Prevention of Mother-Child Transmission of HIV: Towards universal access for women, infants and young children and eliminating HIV and AIDS among children.2007;1-40.Availablefrom: http://apps.who.int/iris/bitstream/10665/43728/1/9789241596015_eng.pdf

8. CSA. Ethiopia Demographic and Health Survey, Central Statistical Agency and ICF International. ICF International Calverton, Maryland, USA. 2012;

9. Federal Ministry of Health E. Report on Progress towards Implementation of the UN Declaration of Commitment on HIV/AIDS Federal Democratic Republic of Ethiopia Federal HIV/AIDS Prevention and Control Office. 2008;(January):1-76.

10. Myer L, Carter RJ, Katyal M, Toro P, El-Sadr WM, Abrams EJ. Impact of antiretroviral therapy on incidence of pregnancy among HIV-infected women in Sub-Saharan Africa: A cohort study. PLoS Med. 2010;

11. Cates W. Family planning: the essential link to achieving all eight Millennium Development Goals. Contraception. 2010.

12. USAID. Family Planning Needs in the Context of the HIV / AIDS Epidemic. Aids. 2004;(November).

13. ZIMSTAT. Zimbabwe Demographic and Health Survey 2015. Statistics (Ber). 2016;

14. Andualem Samuel, Abraham Uliso, Birke Olle, Desalech Dambe, Melkinesh Nigatu and Mende Mensa Sorato*. 2017;2:36-53.

15. Andia I, Kaida A, Maier M, Guzman D, Emenyonu N, Pepper L, et al. Highly active antiretroviral therapy and increased use of contraceptives among HIV-positive women during expanding access to antiretroviral therapy in Mbarara, Uganda. Am J Public Health. 2009;

16. Isah AD, Adewole N, Agida ET, Omonua KI, Wong JYY, Gold EB, et al. Fibroid Uterus: A Case Study. Am Fam Physician. 2017;08(4):725-36.

17. Tadesse L, Submitted T, Health P, Advisor PH, Belachew A. Addis Ababa University , College of Health Sciences, School of Public Health Assessment of Fertility Desire and Family Planning Utilization among HIV positive people who are on antiretroviral treatment , Asella Hospital , Arsi Zone, Oromia Region , 2011. 2011;(May).

18. Sufa A, Abera M, Admasu B. Utilization of Family Planning Methods and Associated Factors among Women Living with HIV Attending ART Clinics in Nekemte Public Health Facilities, East Wollega Zone, Ethiopia. Sci Technol Arts Res J. 2014;

19. Berhane Y, Berhe H, Abera GB, Berhe H. Utilization of Modern Contraceptives among HIV Positive Reproductive Age Women in Tigray, Ethiopia: A Cross Sectional Study. ISRN AIDS. 2013;

20. Khan S, Bradley SEK, Fishel J, Mishra V. Unmet need and the demand for family planning in Uganda: Further analysis of the Uganda Demographic and Health Surveys, 1995-2006 . DHS Furth Anal 
Reports No 60 [Internet]. 2008;1995-2006. Available from:

http://dhsprogram.com/pubs/pdf/FA60/FA60.pdf

21. Worke MD, Bezabih LM, Woldetasdik MA. Utilization of contraception among sexually active HIV positive women attending art clinic in University of Gondar Hospital: A hospital based cross-sectional study. BMC Womens Health [Internet]. 2016;16(1):1-9. Available from:

http://dx.doi.org/10.1186/s12905-016-0348-9

22. AMIN Z. Assessment of Factors Influencing Contraceptives Utilization among Women of Reproductive Age in Jijiga District of Somali National Regional State Addis Ababa University; 2007. 2007;2007.

23. Mishra SR, Joshi MP, Khanal V. Family planning knowledge and practice among people living with HIV in Nepal. PLoS One. 2014;

24. Chibwesha CJ, Li MS, Matoba CK, Mbewe RK, Chi BH, Stringer JSA, et al. Modern contraceptive and dual method use among HIV-infected women in Lusaka, Zambia. Infect Dis Obstet Gynecol. 2011;

25. Tesfaye L, Admassu M, Getachew A, Sharma HR. Fertility desires and family planning demand among HIV-positive clients in follow-up care at antiretroviral treatment unit in Gondar university hospital, Ethiopia. Vulnerable Child Youth Stud. 2012;7(1):20-35.

\section{Tables}

Table1: Socio demographic Characteristics of women living with HIV/AIDS who are on ART follow up in Debre Tabor Referral Hospital in Debre Tabor town , North West Ethiopia, 2020 


\begin{tabular}{|c|c|c|c|}
\hline Variables & & Frequency $(n=415)$ & Percent (\%) \\
\hline \multirow[t]{4}{*}{ Age (years) } & $<25$ & 54 & 13.0 \\
\hline & $25-34$ & 152 & 36.6 \\
\hline & $35-44$ & 142 & 34.2 \\
\hline & $\geq 45$ & 67 & 16.2 \\
\hline \multirow[t]{4}{*}{ Religion } & Orthodox & 381 & 91.8 \\
\hline & Muslim & 24 & 5.8 \\
\hline & Protestant & 8 & 1.9 \\
\hline & other & 2 & 0.5 \\
\hline \multirow[t]{4}{*}{ Ethnicity } & Amhara & 404 & 97.3 \\
\hline & Oromo & 5 & 1.2 \\
\hline & Tigre & 4 & 1.0 \\
\hline & Other & 2 & 0.5 \\
\hline \multirow[t]{5}{*}{ Educational Status } & Illiterate & 47 & 11.3 \\
\hline & Read and write only & 73 & 17.6 \\
\hline & 1-8 Grade & 140 & 33.7 \\
\hline & 9-12 Grade & 134 & 32.3 \\
\hline & $12+$ Grade & 21 & 5.1 \\
\hline \multirow[t]{4}{*}{ Marital status } & Married & 274 & 66.0 \\
\hline & Single & 19 & 4.6 \\
\hline & Divorced & 53 & 12.8 \\
\hline & Widowed & 69 & 16.6 \\
\hline \multirow[t]{6}{*}{ Occupation } & Merchant & 177 & 42.7 \\
\hline & House wife & 144 & 34.7 \\
\hline & Government employee & 31 & 7.5 \\
\hline & Private employee & 24 & 5.8 \\
\hline & Student & 21 & 5.0 \\
\hline & Daily laborer & 18 & 4.3 \\
\hline
\end{tabular}




\begin{tabular}{|llll|} 
Residence & Urban & 362 & 87.2 \\
& Rural & 53 & 12.8 \\
\hline Monthly income & $<3000$ & 319 & 76.9 \\
& $>3000$ & 96 & 23.1 \\
\hline
\end{tabular}

Table 2: Utilization of contraceptives among women living with HIV/AIDS who are on ART follow up in Debre Tabor Referral Hospital in Debre Tabor town, North West Ethiopia, 2020 


\begin{tabular}{|c|c|c|c|}
\hline Variables & & Frequency & Percent \\
\hline \multirow[t]{2}{*}{ Ever used contraceptive } & Yes & 386 & 93.0 \\
\hline & No & 29 & 7.0 \\
\hline \multirow[t]{5}{*}{ Type of contraceptive you ever used( $n=386)^{*}$} & Injectables & 323 & 83.7 \\
\hline & Pills & 278 & 72.0 \\
\hline & Implant & 47 & 12.2 \\
\hline & Condom & 15 & 3.9 \\
\hline & IUCD & 9 & 2.3 \\
\hline \multirow{2}{*}{$\begin{array}{l}\text { Ever used contraceptives after HIV } \\
\text { positive }(n=386)\end{array}$} & Yes & 328 & 85.0 \\
\hline & No & 58 & 15.0 \\
\hline \multirow[t]{2}{*}{ Currently using contraceptive method? $(n=328) *$} & Yes & 137 & 41.8. \\
\hline & No & 191 & 58.2 \\
\hline \multirow[t]{6}{*}{ Type of method currently using $(n=137) *$} & Injectables & 67 & 48.9 \\
\hline & Pills & 33 & 24.1 \\
\hline & Condom & 16 & 11.7 \\
\hline & Dual contraceptives & 11 & 8.0 \\
\hline & Implant & 8 & 5.8 \\
\hline & IUCD & 2 & 1.5 \\
\hline \multirow[t]{2}{*}{ Consistent condom use $(n=27)$} & Yes & 12 & 44.4 \\
\hline & No & 15 & 55.6 \\
\hline \multirow[t]{5}{*}{ Reason for condom use $(n=27) *$} & $\begin{array}{l}\text { To prevent unwanted } \\
\text { pregnancy }\end{array}$ & 19 & 70.4 \\
\hline & Health worker advice & 7 & 25.9 \\
\hline & Fear of other STI & 4 & 14.8 \\
\hline & Partner HIV negative & 3 & 11.1 \\
\hline & Others & 2 & 7.4 \\
\hline \multirow[t]{2}{*}{ Heard about emergency contraceptive $(n=415)$} & Yes & 275 & 66.3 \\
\hline & No & 140 & 33.7 \\
\hline Ever used emergency contraceptive(n=275) & Yes & 42 & 15.3 \\
\hline
\end{tabular}




\begin{tabular}{|llll|}
\hline $\begin{array}{l}\text { The desire to use emergency contraceptive in the } \\
\text { future(n=233) }\end{array}$ & Yes & 233 & 84.7 \\
\cline { 1 - 2 } & No & 32 & 19.9 \\
\hline Reason for not using contraceptive $(\mathbf{n = 1 9 1 ) *}$ & $\begin{array}{l}\text { Not married/in } \\
\text { relationship }\end{array}$ & 129 & 80.1 \\
& Need to get pregnant & 84 & 49.2 \\
& Infertile & 23 & 45.5 \\
& Partners' disapproval & 16 & 8.4 \\
& Other & 7 & 3.7 \\
\hline
\end{tabular}

*multiple responses

Table 3: Client related characteristics of women living with HIV/AIDS who are on ART follow up in Debre Tabor Referral Hospital in North West Ethiopia, 2020

\begin{tabular}{|c|c|c|c|}
\hline Variables & & Frequency & Percent \\
\hline \multirow[t]{2}{*}{ Does your sero status affect your contraceptive use? $(n=415)$} & Yes & 11 & 2.7 \\
\hline & No & 404 & 97.3 \\
\hline \multirow[t]{2}{*}{ Peer support your contraceptive use $(n=415)$} & Yes & 211 & 50.8 \\
\hline & No & 204 & 49.2 \\
\hline \multirow[t]{2}{*}{ Religion influence your contraceptive use $(n=415)$} & Yes & 17 & 4.1 \\
\hline & No & 398 & 95.9 \\
\hline \multirow[t]{2}{*}{ Discuss with partner about contraceptive use? $(n=274)$} & Yes & 211 & 77.0 \\
\hline & No & 63 & 23.0 \\
\hline \multirow[t]{2}{*}{ Spouse approval $(n=211)$} & Yes & 200 & 94.8 \\
\hline & No & 11 & 5.2 \\
\hline
\end{tabular}

Table 4: Service delivery related factors for use of modern FP methods among women living with HIV/AIDS who are on ART follow up in Debre Tabor Referral Hospital in North West Ethiopia, 2020 


\begin{tabular}{|c|c|c|c|}
\hline Variables & & $\begin{array}{l}\text { Frequency } \\
\text { (n) }\end{array}$ & Percent \\
\hline \multirow[t]{2}{*}{ Receive counseling about Contraceptive use in ART unit(n=415) } & Yes & 377 & 90.8 \\
\hline & No & 38 & 91.6 \\
\hline \multirow{2}{*}{$\begin{array}{l}\text { Availability of ART \& PMTCT service affect your pregnancy desire } \\
(n=415)\end{array}$} & Yes & 132 & 31.8 \\
\hline & No & 283 & 68.2 \\
\hline \multirow[t]{2}{*}{ Access to Contraceptives $(n=386)$} & Yes & 369 & 95.6 \\
\hline & No & 17 & 4.4 \\
\hline \multirow[t]{2}{*}{ Hospital meet your needs of contraceptives $(n=386)$} & Yes & 377 & 97.7 \\
\hline & No & 9 & 2.3 \\
\hline \multirow{2}{*}{$\begin{array}{l}\text { Side effect of contraceptives influences your method of choice? } \\
(n=386)\end{array}$} & Yes & 119 & 30.8 \\
\hline & No & 267 & 69.2 \\
\hline
\end{tabular}

Table 5: Ch-square test showing factors associated with modern FP utilization among women living with HIV/AIDS who are on chronic care follow up in Debre Tabor Referral Hospital in North West Ethiopia, 2020 


\begin{tabular}{|c|c|c|c|c|c|c|c|c|}
\hline \multirow[t]{2}{*}{ Variables } & & \multicolumn{7}{|c|}{ Modern contraceptive use } \\
\hline & & Yes & No & & Total & & $x^{2}$ & $\begin{array}{l}P \text { - } \\
\text { value }\end{array}$ \\
\hline \multirow[t]{5}{*}{ Educational status } & Illiterate & 38 & \multirow{2}{*}{\multicolumn{2}{|c|}{$\begin{array}{l}9 \\
13 \\
4\end{array}$}} & 47 & & \multirow[t]{5}{*}{$=33.9$} & \multirow[t]{5}{*}{$=0.000$} \\
\hline & Read\&write & 60 & & & 73 & & & \\
\hline & 1-8 Grade & 136 & 2 & & 140 & & & \\
\hline & 9-12 Grade & \multirow[t]{2}{*}{13220} & \multirow{2}{*}{\multicolumn{2}{|c|}{1}} & 134 & & & \\
\hline & $12+$ Grade & & & & 21 & & & \\
\hline \multirow[t]{2}{*}{ Knowledge of modern FP } & Yes & 371 & \multirow[t]{2}{*}{2} & \multirow[t]{2}{*}{27} & \multirow[t]{2}{*}{373} & \multirow[t]{2}{*}{42} & \multirow[t]{2}{*}{$=236$} & \multirow[t]{2}{*}{$=0.000$} \\
\hline & No & 15 & & & & & & \\
\hline \multirow{3}{*}{$\begin{array}{l}\text { No of children current } \\
\text { have }\end{array}$} & No child & \multirow{3}{*}{$\begin{array}{l}48 \\
187 \\
151\end{array}$} & \multirow[t]{3}{*}{4} & \multirow[t]{3}{*}{1114} & \multirow[t]{3}{*}{$\begin{array}{l}52 \\
198\end{array}$} & \multirow{3}{*}{165} & \multirow[t]{3}{*}{$=1.23$} & \multirow[t]{3}{*}{$=0.540$} \\
\hline & $\begin{array}{l}1-2 \\
\text { child/ren }\end{array}$ & & & & & & & \\
\hline & $\begin{array}{l}>=3 \\
\text { children }\end{array}$ & & & & & & & \\
\hline \multirow{2}{*}{$\begin{array}{l}\text { Spouse approval of } \\
\text { contraceptive use }\end{array}$} & Yes & \multirow[t]{2}{*}{1811} & \multirow[t]{2}{*}{19} & \multirow[t]{2}{*}{10} & 200 & & \multirow[t]{2}{*}{$=58.3$} & \multirow[t]{2}{*}{$=0.000$} \\
\hline & No & & & & 11 & & & \\
\hline \multirow[t]{2}{*}{ Peer support } & Yes & \multirow{2}{*}{$\begin{array}{l}198 \\
188\end{array}$} & \multirow[t]{2}{*}{13} & \multirow[t]{2}{*}{16} & 211 & & \multirow[t]{2}{*}{$=0.451$} & \multirow[t]{2}{*}{$=0.502$} \\
\hline & No & & & & 204 & & & \\
\hline \multirow{2}{*}{$\begin{array}{l}\text { Receive counseling about } \\
\text { modern FP }\end{array}$} & Yes & 37115 & 6 & 23 & 377 & & $=184$ & $=0.000$ \\
\hline & No & & & & 38 & & & \\
\hline
\end{tabular}

\section{Figures}




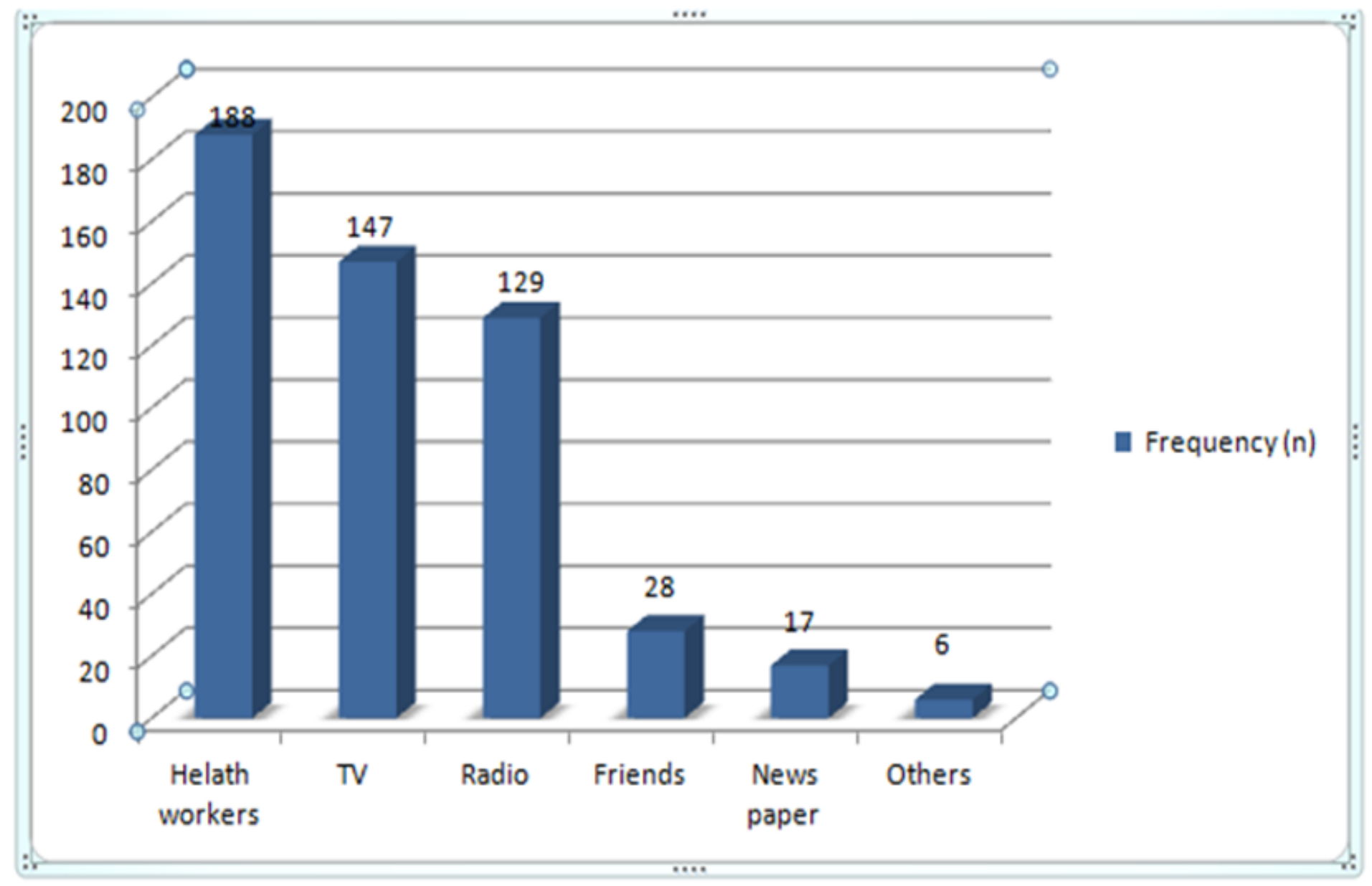

Figure 1

Source of information about contraceptives of women living with HIV/ADIS who are on ART follow up in Debre Tabor Referral Hospital, February 2020 


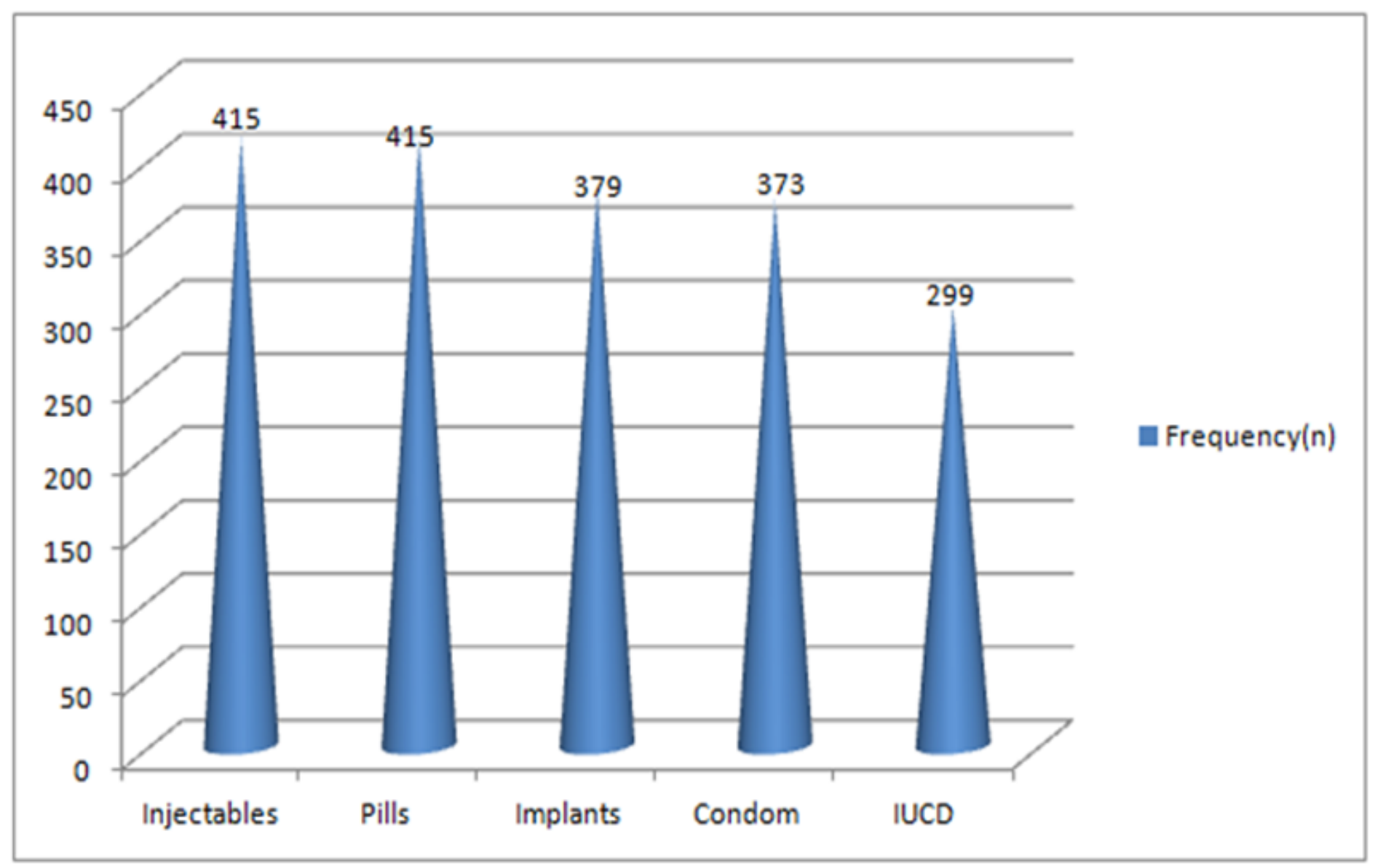

Figure 2

Frequency distriburion of contraceplive methods ever heard by women living with 111ViAIDS who are on ART follow up in Debre Tabor Referral Hospitil, February 2020 